\title{
Role of transabdominal ultrasound in detection of ectopic pregnancy
}

\author{
Narayan Bikram Thapa ${ }^{1}$, Yam Prasad Dwa ${ }^{2}$ \\ ${ }^{1}$ Associate Professor, Department of Radiology, ${ }^{2}$ Assistant professor, Department of Obstetrics and \\ Gynecology, Kist Medial College Teaching Hospital, Kathmandu, Nepal
}

\section{Correspondence \\ Dr Narayan Bikram Thapa \\ Department of Radiology, Kist Medial College Teaching \\ Hospital, Kathmandu, Nepal \\ Email: \\ nadudocradio@yahoo.com}

DOI: http://

dx.doi.org/10.3126/

jcmsn.v12i1.14397

\begin{abstract}
Background \& Objectives: Ectopic pregnancy is one of the common medical emergencies encountered in the clinical practice. Confirmation of diagnosis is usually done by urine pregnancy test and transabdominal sonography. Thus, the present study is carried out to determine the role of transabdominal ultrasonography in the diagnosis of ectopic pregnancy by comparing the ultrasonography findings with that of operative and histopathology and to evaluate clinical profile of the women with confirmed ectopic pregnancy. Materials \& Methods: Transabdominal ultrasound record of patients referred for first trimester ultrasound, from January 2008 to December 2015, at radiology department of Kist medial college teaching hospital were reviewed to identify patients with ectopic pregnancy. Among these patients those who underwent surgery and histopathology confirmed ectopic pregnancies were identified and their medical records were retrieved. Ultrasound and clinical profile were recorded and statistically analyzed. Results: There were 19 patients with ultrasound diagnosis of ectopic pregnancy among 1480 first trimester ultrasound record. Among these patients, ectopic pregnancy was confirmed on 18 patients. Ultrasound diagnosis included adnexal mass with pelvic fluid in $15(83.3 \%)$ patients and pelvic fluid without adnexal mass in 4 $(16.7 \%)$ patients. The study result revealed that sensitivity of transabdominal ultrasonography was $100 \%$ and specificity was $99.9 \%$. Positive predictive value and negative predictive value of transabdominal ultrasonography was $94 \%$ and $100 \%$. Conclusion: The transabdominal ultrasound accurately diagnose ruptured ectopic pregnancy

Key words: Adnexal mass, ectopic pregnancy, free fluid, transabdominal ultrasound
\end{abstract}

Citation: Thapa NB, Dwa YP. Role of transabdominal ultrasound in detection of ectopic pregnancy JCMS Nepal. 2016;12(1):1-4.

\section{INTRODUCTION}

Ectopic pregnancy should always be considered in the women of reproductive age presenting with acute lower abdominal pain. The incidence of ectopic pregnancy is up to 16.9 per 1000 reported pregnancies and is increasing. ${ }^{1,2}$ The associated mortality has decreased markedly to 0.5 deaths per 1000 pregnancies, mainly because of early diagnosis and treatment before rupture. ${ }^{3}$ Though the tubal rupture in the ectopic pregnancy could be suspected clinically, many a times the symptoms could be subtle and may be missed clinically. Ultrasonography is a cheap, widely available, simple, rapid and noninvasive diagnostic modality in the diagnosis of suspected ectopic pregnancy. ${ }^{4}$ Diagnosis of ectopic pregnancy is improved by recent ultrasound equipments and ability to quantify serum Beta hCG level. Nonetheless, the diagnosis remains a challenge. Abdominal ultrasonographic accuracy can be affected by factors such as obesity, insufficient filling of bladder and obscuration of pelvic structures by bowel gas. The combination of ultrasound scanning with beta hCG was found highly contributory to the determination of the existence of an ectopic pregnancy. If a transabdominal examination is not definitive, a transvaginal sonography (TVS) or transperineal scan should be performed whenever possible. ${ }^{5}$

With TVS, the pelvic structures could be visualized closely and resolution of the image improves so it has been recommended for early detection of intrauterine pregnancy as well as to characterization of extrauterine findings. However, separate transducer is required for TVS which might not be readily available in the clinical settings especially of the developing countries. Hence, the clinician has to rely on the clinical examination finding, urine pregnancy test and abdominal ultrasound for 
the diagnosis of ectopic pregnancy.

This study was carried out to evaluate role of transabdominal ultrasonography (TAS) in the diagnosis of suspected ectopic pregnancy by comparing the findings with that of operative and histopathology findings and thus to find out the sensitivity, specificity and accuracy of transabdominal ultrasonography in the evaluation of ectopic pregnancy. This study also aims to evaluate clinical profile of the women with confirmed ectopic pregnancy

\section{MATERIALS AND METHODS}

Among the patients referred to radiology department of Kist medial college teaching hospital from January 2008 to December 2015 for first trimester ultrasound, those with the diagnosis of either proven or suspected ectopic pregnancy were identified from ultrasound record. Among these patients, those who underwent surgical treatment for ectopic pregnancies by laparotomy were identified and their medical records were retrieved. Only those patient whose complete medical, surgical records including histopathological findings could be retrieved, were included in the study.

\section{Variables of interest}

TAS was carried out preoperatively in all cases by one of the three radiologists working at Kist teaching hospital. Siemens Acuson X600 and Siemens Acuson X 300 machine with transabdominal probe $\mathrm{C} 6-2$ were used for abdominal scanning. During the first trimester ultrasound scanning, it is our routine practice to take at least, three pictures: one of the uterus in a strictly midsagittal plane from the uterine cervix to the fundus; one of each ovary in their greater diameter. In case of abnormal extra-uterine finding one or more picture are taken. All sonograms were again carefully reviewed by single radiologist for the purpose of the study. Ultrasonograms for ectopic pregnancy diagnosis were coded: positive if there was presence of fluid in pouch of doglus or extrauterine sac/ adnexal mass and negative in presence of intrauterine gestational sac and normal pelvis. Similarly, the amount of hemoperitoneum is

Table 1: Accuracy of TAS in detecting ectopic pregnancy

\begin{tabular}{ll} 
Sensitivity & $100 \%$ \\
\hline Specificity & $99.9 \%$ \\
\hline Positive predictive value & $94 \%$ \\
\hline Negative predictive value & $100 \%$ \\
\hline
\end{tabular}

Table 2: TAS findings of study population

\begin{tabular}{ll} 
USG findings & $\mathrm{n}(\%)$ \\
\hline Adnexal mass with pelvic fluid & $15(83.3 \%)$ \\
\hline Pelvic fluid without adnexal mass & $4(16.7 \%)$ \\
Mild hemoperitoneum & $7(38.9 \%)$ \\
\hline Mod hemoperitoneum & $9(50.0 \%)$ \\
\hline Severe hemoperitoneum & $2(11.1 \%)$ \\
Thickened endometrium & 1
\end{tabular}

classified as mild, moderate and severe.

The following parameters were collected from the medical records of the operated patient like age, gravidity, parity, gestational age, the existence of vaginal bleeding and abdominal pain, pre operative urinary hCG positivity, presence of syncope and shock. Similarly, laparotomy findings rupture and presence of the site of rupture, estimated blood loss and histopathology findings were collected.

\section{Statistical analysis}

The collected data was analyzed accordingly using SPSS version 16. The investigation findings were calculated as frequency distribution. Histopathology was considered as gold standard and it was compared with transabdominal sonography. Performance of TAS was calculated by using sensitivity, specificity, positive predictive value and negative predictive value.

\section{RESULT}

During the study period, first trimester ultrasound was done for 1480 women. Ultrasound finding was positive for ectopic pregnancy in 19 patients all of whom underwent surgical treatment. Among these 19 patients, one patient with preoperative diagnosis of ectopic turned out to be twisted ovarian cyst. Hence only 18 histopathologically confirmed cases of ectopic pregnancy were analyzed for the clinical profile.

The study result revealed that sensitivity of TAS was $100 \%$ and specificity was $99.9 \%$. Positive predictive value and negative predictive value of TAS were $94 \%$ and $100 \%$ respectively.

Four patients had only free fluid without adnexal mass (figure 1). A positive finding of an adnexal mass with mild-to-large amount of free fluid was present in 15 cases $(83.3 \%$ )(figure 2). Among our 18 study cases, sonography showed a mild hemorrhage in $7(38.9 \%)$ cases, moderate hemorrhage in $9(50.0 \%)$ and severe hemorrhage in $2(11.1 \%)$ cases. Thickened endometrium was 
Table 3: Clinical characteristic and operative findings of study population

\begin{tabular}{|c|c|c|}
\hline & No. & Percentage \\
\hline Amenorrhea & 10 & 55.6 \\
\hline Vaginal bleeding & 12 & 66.7 \\
\hline Lower abdominal pain & 18 & 100 \\
\hline Syncope & 2 & 11.1 \\
\hline Shock & 1 & 5.5 \\
\hline Urine pregnancy test positive & 18 & 100 \\
\hline \multicolumn{3}{|l|}{$\begin{array}{l}\text { Operative findings } \\
\text { Site of ectopic }\end{array}$} \\
\hline Left fallopian tube & 4 & 22 \\
\hline Ampullary portion & 3 & \\
\hline Isthmus & 1 & \\
\hline Right fallopian tube & 14 & 78 \\
\hline Ampullary portion & 11 & \\
\hline Isthmus & 2 & \\
\hline Cornual & 1 & \\
\hline Tubal rupture & 15 & 83.3 \\
\hline \multicolumn{3}{|l|}{ Hemoperitoneum } \\
\hline$\leq 500$ & 7 & 38.9 \\
\hline$\leq 1000$ & 7 & 38.9 \\
\hline 1000 above & 4 & 22.2 \\
\hline \multicolumn{3}{|l|}{ Surgery } \\
\hline Salphingostomy & 1 & 5.6 \\
\hline Salphingetomy & 16 & 83.3 \\
\hline $\begin{array}{l}\text { Salphingetomy with } \\
\text { oophoretomy }\end{array}$ & 2 & 11.1 \\
\hline
\end{tabular}

noted in one patient (Table 2).

As demonstrated in the table 3 , the mean age was 28.5 years, mean gravidity was $2 \pm 1.81$ and the mean gestational ages calculated by last menstrual period was 42.84 days. There was history of amenorrhea only in $10(55.6 \%)$ cases, history of vaginal bleeding in $12(66.7 \%)$ patients and lower abdominal pain in $18(100 \%)$ patients.

Surgery was performed within one day of the ultrasonography diagnosis in all cases. Fifteen $(83.3 \%)$ had rupture of fallopian tube. Tubal rupture was on left side in only four cases. Salpingectomy was done in all cases expect one where salpingostomy was done and salpingectomy with oophorectomy was also done in three cases. (Table 3)

\section{DISCUSSION}

All women with an ectopic pregnancy were symptomatic in the present study. The timing of the scans at the time of diagnosis was 42.8 days which is comparable to detection of ectopic pregnancy by TVS.

Nahar et $\mathrm{al}^{6}$ did cross sectional study comparing diagnostic accuracy of TAS and TVS in 30 patients with suspected ectopic pregnancy and found that sensitivity and specificity of $73.1 \%$ and $92.3 \%$ respectively and Positive predictive value and negative predictive value of $95 \%$ and $30 \%$ respectively. Similarly study conducted by $\mathrm{Malik}^{7}$ in 100 patients and found sensitivity of $82.3 \%$, specificity of $93.3 \%$, positive predictive value $98.5 \%$, negative predictive value $482 \%$. The findings of the study by Malik AS were similar to the findings observed by Hopp. ${ }^{8}$ Kim et $\mathrm{al}^{9}$ found transabdominal ultrasonography was $95.9 \%$ sensitive, $73.9 \%$ specific and positive predictive value was $73.9 \%$. In the present study, $100 \%$ sensitivity, $99.9 \%$ specificity, $100 \%$ positive predictive value and $94 \%$ negative predictive values were observed which was higher than study conducted by others in the past. All patients had ruptured ectopic at the time of presentation. In our clinical practice, women are not routinely screened with TVS. Hence the ectopic pregnancy is usually diagnosed when it is complicated by tubal rupture and/or hemoperitoneum. Diagnosis of this condition early in pregnancy would have given an opportunity to the obstetrician to initiate medical management avoiding the emergency surgery. ${ }^{10}$ Neither the gestational sac nor embryo was noted among the enrolled patients. Failure to include patients with adnexal mass with confirmation of ectopic pregnancy by TVS which could have detected asymptomatic cases is the most important limitation of this study. Few patients with suspected ectopic pregnancy on TAS opted to go to other hospitals for surgery so these were not also excluded in the present study. Inclusion of such cases could have increase the sample size. However, due to absence to follow up and unavailability of surgical and histological report of those patients, we excluded such cases from our study.

The age of presentation and parity observed in the present study is similar to the result of the study done by Pal et $\mathrm{al}^{11}$ in India and Malik ${ }^{7}$ in Pakistan. $\mathrm{Pal}$ et $\mathrm{al}^{11}$ found that the incidence of ectopic pregnancy was maximum (37.6\%) in age group of 26-30 year and among patients with 1-3 para (45\%). 
Similarly Malik et $\mathrm{al}^{7}$ conducted study among 100 patients where maximum incidence of $50 \%$ in the same group was reported and among patients with para two $(39.2 \%)$. In the study done by Mufti et al ${ }^{12}$ among 114 patients, the incidence was maximum $55.25 \%$ in the age group of $26-30$ years whereas the incidence was the most common $53.50 \%$ among nullipara. In the present study, pain was the commonest symptom $(100 \%)$ followed by vaginal bleeding in $12(66.7 \%)$ of cases and amenorrhoea $(55.6 \%)$. These results are quite similar with study of Pal et $\mathrm{al}^{12}$ and Malik et al. ${ }^{7}$ In the present study, only $5.5 \%$ of patients were admitted in state of shock as compared with $9 \%$ of patients with shock in study conducted by Afridi et al. ${ }^{13}$ The incidence of chronic ectopic pregnancy usually ranges from $8.6 \%$ to $20.3 \%$ of all ectopic pregnancies. ${ }^{14,15}$ Absence of chronic ectopic and those with negative urine pregnancy test indicate failure to detect those cases in this study

Salpingectomy was done in the majority $(83.3 \%)$ of patients and salpingostomy was done in $11.1 \%$ patient. Higher rate of salphingetomy is because of late presentation of enrolled patients with rupture ectopic. This could have been avoided if the cases had been diagnosed before rupture of the tube. However, this finding is similar to the findings of study done by Deeba et $\mathrm{al}^{15}$ who observed rate of salphingetomy and salphingostomy $89.8 \%$ and $4.3 \%$ respectively. The decision to perform a salpingostomy or salpingectomy is often made intraoperatively based on the extent of damage to the affected and contra-lateral tubes but it is also dependent on the patient's history of previous ectopic pregnancy and wish for future fertility, availability of assisted reproductive technology and the skill of the surgeon. ${ }^{16}$

\section{CONCLUSION}

This study shows that transabdominal ultrasonography is one of the reliable basic imaging modality for detection of ruptured ectopic pregnancy.

\section{REFERENCES}

1. Doyle MB, DeCherney AH, Diamond MP. Epidemiology and etiology of ectopic pregnancy. Obstet Gynecol Clin North Am. 1991;18:1-17. PMID:1923251

2. Stabile I, Grudzinskas JG. Ectopic pregnancy: a review of incidence, etiology and diagnostic aspects. Obstetric and gynecological survey. 1990;45:335-47. DOI: 10.1097/00006254-199006000-00001

3. Chang J, Elam-Evans LD, Berg CJ, et al. Pregnancy related mortally surveillance- United States, 1991-1999.
MMWR Surveill Summ. 2003;52:1-9. PMID:12825542.

4. Weckstein LN. Current perspective on ectopic pregnancy. Obstet Gynecol Surv; 1985; 40: $259-72$. DOI: $\quad 10.1097 / 00006254-198505000-00001$. PMID:3158847.

5. Kirk E, Daemen A, Papageorghiou AT, Bottomley C, Condous G, Moore BD, Timmerman D et al. Why are some ectopic pregnancies characterized as pregnancies of unknown location at the initial transvaginal ultrasound examination? Acta Obstet Gynecol Scand 2008; 87:1150 1154. DOI: $\quad 10.1080 / 00016340802443822$. PMID: 18846452.

6. MN Nahar, MA Quddus, A Sattar, M Shirin, A Khatun, R Ahmed et al. Comparison of transvaginal and transabdominal ultrasonography in the diagnosis of ectopic pregnancyBangladesh Med Res Counc Bull. 2013;39:104-8.

7. Malik AS, Malik S, Maqbool A. Comparison of Transabdominal and Transvaginal Sonography in the Diagnosis of Ectopic Pregnancy. [Internet]. [cited 2015 Nov 12]. Available from: http://pjmhsonline.com

8. Hopp H, Schaar P, Entezami M, Ebert A, Hundertmark S, Vollert $\mathrm{W}$ et al. Diagnostic reliability of vaginal ultrasound in ectopic pregnancy. Geburtshilfe Frauenheilkd. 1997:55:666-70 DOI: $10.1055 / \mathrm{s}-2007-1022310$. PMID:8582583.

9. Kim DS, Chung SR, Park MI, Kim YP; Comparative review of diagnostic accuracy in tubal pregnancy: A 14year survey of 1040 cases. Obstetrics and Gynaecology. 1987;70(4):547-54.

PMID:2442686.

10. Kirk E \& Bourne T. The nonsurgical management of ectopic pregnancy. Curr Opin Obstet Gynecol. 2006;18:587-93. DOI: 10.1097 GCO.0b013e3280105886. PMID: 17099327.

11. Pal A, Gupta KB, Sarin RA. Study of ectopic and high risk factors in Himachal Pardesh. J Indian Med Assoc. 1996;94:172-3. PMID:8855569.

12. Mufti S, Rather S, Mufti S, Rangrez AR, Khalida W. Ectopic pregnancy: An analysis of 114 cases. JKPractitioner. 2012;17(4):20-3.

13. Afridi B, Maqsood L. Ectopic Pregnancy. Pakistan J Obstret Gynecol. 1991;4:55-9.

14. Turan C, Ugur M, Dogan M, Ekici E, Vicdan K, Gökmen O. Transvaginal sonographic findings of chronic ectopic pregnancy. Eur J Obstet Gynecol Reprod Biol. 1996 Aug;67(2):115-9. DOI: 10.1016/0301-2115(96)02443-8.

15. Deeba F, Khan B, Khattak SN. Ectopic pregnancy management in Ayub Teaching Hospital Abbottabad: A ten year survey. J Ayub Med Coll Abbottabad. 2012;24(3 $-4): 82-4$.

16. Barnhart KT. Ectopic Pregnancy. N Eng J Med. 2009;361:379-87. PMID:19625718. 